\title{
Article \\ Dimerization of Acetylene to Monovinylacetylene (MVA) by Bimetallic Zr/Cu Catalyst in Nieuwland Catalytic System
}

\author{
Leng Zheng ${ }^{1}$, Ruolin Lin ${ }^{1}$, Dingjie Luo ${ }^{1}$, Liang Guo ${ }^{1, *}$ and Jinli Zhang ${ }^{2, *} \mathbb{C}$ \\ 1 School of Chemistry and Chemical Engineering, Key Laboratory for Green Processing of Chemical \\ Engineering of Xinjiang Bingtuan, Shihezi University, Shihezi 832003, China; zfg1523@163.com (L.Z.); \\ linruoling163@163.com (R.L.); dingjieluo@163.com (D.L.) \\ 2 School of Chemical Engineering and Technology, Tianjin University, Tianjin 300072, China \\ * Correspondence: guoliang_xj@163.com (L.G.); zhangjinli@tju.edu.cn (J.Z.)
}

check for

updates

Citation: Zheng, L.; Lin, R.; Luo, D.;

Guo, L.; Zhang, J. Dimerization of Acetylene to Monovinylacetylene (MVA) by Bimetallic $\mathrm{Zr} / \mathrm{Cu}$ Catalyst in Nieuwland Catalytic System.

Molecules 2022, 27, 602 .

https://doi.org/10.3390/

molecules27030602

Academic Editors: Vito Capriati and Jing Liu

Received: 18 November 2021

Accepted: 14 January 2022

Published: 18 January 2022

Publisher's Note: MDPI stays neutral with regard to jurisdictional claims in published maps and institutional affiliations.

Copyright: (C) 2022 by the authors. Licensee MDPI, Basel, Switzerland. This article is an open access article distributed under the terms and conditions of the Creative Commons Attribution (CC BY) license (https:// creativecommons.org/licenses/by/ $4.0 /)$.

\begin{abstract}
Nieuwland catalyst is a key step in the dimerization of acetylene. Various zirconium metal additives incorporating Nieuwland catalysts were prepared, and their catalytic performances were assessed in acetylene dimerization. Different characterization techniques (i.e., thermogravimetric analysis, temperature-programmed reduction, $\mathrm{X}$-ray diffraction, $\mathrm{X}$-ray photoelectron spectroscopy, hydrogen ion concentration measurement and transmission electron microscopy) were employed in this study. The best catalytic performance was obtained over zirconium-acetylacetonate-incorporated Nieuwland catalysts, with an acetylene conversion of $53.3 \%$ and a monovinylacetylene selectivity of $87.4 \%$. Based on these results, the zirconium acetylacetonate additive could reduce the types of transition state complexes, and it could also change the morphology of the catalyst. In addition, the additives could significantly inhibit the occurrence of trimerization products and polymers. Hence, the conversion of acetylene, monovinylacetylene selectivity, and stability of the Nieuwland catalysts were enhanced.
\end{abstract}

Keywords: Nieuwland catalyst; acetylene dimerization; monovinylacetylene; Cu-based catalyst; bimetallic catalyst

\section{Introduction}

Chloroprene rubber (CR), which possesses excellent physical and chemical properties, is one of the five engineering plastics and is widely used in various applications, such as industrial applications, agricultural activities, and daily life [1-4]. Generally, two methods are currently employed for the industrial production of CR. One is a butadiene-based method, and the other is an acetylene-based method [5-7]. With the gradual development of coal resources, the acetylene-based method has received extensive attention in China because of the coal resource abundance [8]. Dimerization of acetylene to monovinylacetylene is the key step in the acetylene-based method, and the Nieuwland catalyst (NC) is often used with composites of $\mathrm{CuCl}-\mathrm{NH}_{4} \mathrm{Cl}$ (or $\mathrm{KCl}$ )- $\mathrm{HCl}-\mathrm{H}_{2} \mathrm{O}$. However, it is necessary to address the following challenges. The conversion rate of acetylene and the selectivity of MVA are low, and the contact between acetylene and an active component within a gas-liquid reactor is uneven. The solubility of acetylene in water is poor, and this can lead to an inadequate gas content in the liquid. Furthermore, the duration of the contact between the reactants and active components is short. The poor contact between acetylene and the catalyst is further aggravated by the presence of by-products, which can easily cover the surfaces of the active components of the catalyst. To mitigate this issue, $\mathrm{Cu}^{+}$can catalyze the dimerization reaction, hydrochlorination, and acetaldehyde reaction, which allows the continual dimerization of acetylene to MVA. This reaction can produce divinyl acetylene (DVA) and other polymers. Thus, the focus of this research is to find a catalyst that can achieve (1) good contact between acetylene and the active components, (2) reduce 
the occurrence of side reactions, and (3) increase the effective utilization rate of acetylene during the dimerization reaction.

In recent years, the reaction system has been continuously optimized by numerous researchers. Various strategies, such as adding a second metal to develop a synergistic catalyst, ligand modification, catalytic mechanism, and process strengthening, have been proposed, with encouraging results reported. Use isotope labeling and other methods to study the reaction mechanism and explore the cause of catalyst deactivation $[9,10]$. From the perspective of process enhancements, electric field enhancement [11], high-shear strengthening [12], and the incorporation of graphene can improve the conversation of $\mathrm{C}_{2} \mathrm{H}_{2}$ in acetylene dimerization [13]. It has been reported that MVA selectivity can be enhanced by using a bimetallic synergistic catalyst (adding a second metal) [14-16]. Ligand modification has been reported to be effective for improving the catalytic activity and stability of the catalyst after adding ligands [17-20]. Changing the catalytic system (i.e., replacing the aqueous Nieuwland catalyst with an organic phase) can significantly increase the conversion rate of acetylene $[16,21,22]$. The catalyst system can also be changed from a gas-liquid bubbling fluidized bed reactor to a gas-solid phase reactor [23], which can address the issue of catalyst recovery but deactivated quickly. In addition, side-reactions of acetylene hydration and acetylene dimerization often occur in the Nieuwland catalyst, which results in a low selectivity of MVA.

Although these studies found that the addition of a second metal can significantly improve the selectivity of MVA ( $90 \%)$ and the stability of the catalyst in the acetylene dimerization reaction, the conversion rate of acetylene was reduced significantly (10-15\%). Therefore, we seek a metal promoter that can change the morphology of the catalyst and enhance the conversion rate of acetylene. In this work, the addition of zirconium metal to the catalyst was found to promote the MVA selectivity and conversion of $\mathrm{C}_{2} \mathrm{H}_{2}$ through a series of comparisons, because a sufficient bubbling effect strengthened the contact between acetylene and the catalyst.

\section{Experimental}

\subsection{Materials}

$\mathrm{C}_{2} \mathrm{H}_{2}$ (gas, 99.5\%) and $\mathrm{N}_{2}$ (gas, 99.998\%) were purchased from Shanghai Weichuang Standard Gas Analytical Technology Co., Ltd (Shanghai, China). Zirconium nitrate pentahydrate $\left(\mathrm{Zr}_{1}\right)$, zirconium butoxide $\left(\mathrm{Zr}_{2}\right)$, zirconium oxychloride octahydrate $\left(\mathrm{Zr}_{3}\right)$, zirconium chloride $\left(Z_{4}\right)$, zirconium acetylacetonate $\left(Z r_{5}\right)$, acetylacetone $\left(C_{1}\right)$, acetone $\left(C_{2}\right)$, acetic acid $\left(\mathrm{C}_{3}\right), \mathrm{NH}_{4} \mathrm{Cl}$, and $\mathrm{CuCl}$, were purchased from Macklin Chemical Reagent Co., Ltd (Xi'an, China) and all reagents were of analytical grade directly used without purification. Deionized water was prepared in the laboratory using a standard reagent-type ultrapure water machine (FBZ1002-SUP, Qingdao Flom Technology Co., Ltd., Qingdao, China).

\subsection{Catalyst Preparation}

The Nieuwland catalyst used as a control was labeled NC, and the catalysts containing $\mathrm{Zr}_{X}$ additive were denoted as $\mathrm{Zr}_{X} / \mathrm{NC}$, where $\mathrm{X}$ denotes the different kinds of anions added. The amount $\mathrm{Zr}_{\mathrm{X}}$ added was calculated in moles based on the amount of $\mathrm{CuCl}$ added.

The Nieuwland catalysts were prepared by dissolving $5.35 \mathrm{~g}(0.1 \mathrm{~mol})$ of $\mathrm{NH}_{4} \mathrm{Cl}$ and $9.9 \mathrm{~g}(0.1 \mathrm{~mol})$ of $\mathrm{CuCl}$ in $10 \mathrm{~mL}$ of deionized water at $80^{\circ} \mathrm{C}$, and a reddish-brown homogeneous mixture was obtained. A certain molar amount of $\mathrm{Zr}_{X}$ was then added to the NC, which varied based on the different metal additives, to achieve a desired molar quantity of zirconium ions. Before the reaction, the reactor was purged with nitrogen to eliminate the air. Stirring continued for at least $15 \mathrm{~min}$ until the solids had completely dissolved and the expected catalyst was obtained. The fresh and used NC and $\mathrm{Zr}_{5} / \mathrm{NC}$ were left in the refrigerator at $3{ }^{\circ} \mathrm{C}$ for $6 \mathrm{~h}$ (the $\mathrm{NC}$ and $\mathrm{Zr}_{5} / \mathrm{NC}$ after $8 \mathrm{~h}$ of reaction are referred to as used $\mathrm{NC}$ and $\mathrm{Zr}_{5} / \mathrm{NC}$, respectively). They were then filtered from the catalytic solution, washed with water, and dried in a vacuum oven at $80^{\circ} \mathrm{C}$ to obtain a solid catalyst that was ready for characterization. 


\subsection{Catalytic Activity Analysis and Evaluation}

The catalysts were tested in a self-designed bubble column reactor (length: $400 \mathrm{~mm}$, outer diameter: $40 \mathrm{~mm}$, inner diameter: $10 \mathrm{~mm}$ ) that was made of glass, which was used for the acetylene dimerization reaction. Pure acetylene was then passed through the reactor. After the reaction product was dried, the gas phase products were analyzed on-line using a GC-2014C gas chromatograph (Shimadzu Corporation, Tokyo, Japan) immediately.

The conversion of acetylene $\left(\mathrm{X}_{\mathrm{A}}\right)$ and the selectivity of the products $\left(\mathrm{S}_{\mathrm{MVA}}\right)$ were calculated as follows:

$$
\begin{gathered}
\mathrm{X}_{\mathrm{A}}=\frac{\varphi_{1}+2 \varphi_{2}+2 \varphi_{3}+3 \varphi_{4}}{\varphi_{1}+2 \varphi_{2}+2 \varphi_{3}+3 \varphi_{4}+\varphi_{5}} \times 100 \%, \\
\mathrm{~S}_{\mathrm{MVA}}=\frac{2 \varphi_{2}}{\varphi_{1}+2 \varphi_{2}+2 \varphi_{3}+3 \varphi_{4}} \times 100 \%,
\end{gathered}
$$

where $\varphi_{1}, \varphi_{2}, \varphi_{3}, \varphi_{4}$ and $\varphi_{5}$ are the volume fractions of the outlet composition, $\mathrm{CH}_{3} \mathrm{CHO}$, MVA, Chloroprene (CP), and Divinylacetylene (DVA), $\mathrm{C}_{2} \mathrm{H}_{2}$, respectively.

\subsection{Catalyst Characterization}

The $\mathrm{pH}$ of the catalyst was measured using a pen-like PHB-3 meter (Shanghai Sanxin Instrument Factory, Shanghai, China).

The metal contents in the catalysts were determined using inductively coupled plasmaatomic emission spectroscopy (ICP-OES, Agilent 5110, Agilent Technologies, Inc., Santa Clara, CA, USA).

Thermogravimetric analysis (TGA) and differential scanning calorimetry (DSC) of the samples were performed using a NETZSCH STA 449F3 Jupiter thermogravimetricdifferential scanning calorimeter and a simultaneous thermal analyzer (NETZSCH Group, Selb, Germany) in a nitrogen atmosphere at a flow rate of $30 \mathrm{~mL} \mathrm{~min}^{-1}$. The temperature was increased from 50 to $900{ }^{\circ} \mathrm{C}$ at a heating rate of $10^{\circ} \mathrm{C} \mathrm{min}^{-1}$.

Temperature-programmed reduction (TPR) experiments (ASAP 2720, Mike Instruments ltd., Georgia, US) were performed in a micro-flow reactor fed with a $10.0 \% \mathrm{H}_{2}-\mathrm{Ar}$ mixture flowing at a rate of $120 \mathrm{~mL} \mathrm{~min}^{-1}$. Prior to each test, the samples were treated with $\mathrm{N}_{2}$ gas at $80^{\circ} \mathrm{C}$ for $30 \mathrm{~min}$. The temperature was then increased from 80 to $900{ }^{\circ} \mathrm{C}$ at a heating rate of $10^{\circ} \mathrm{C} \mathrm{min}^{-1}$, and the temperature was held at $900{ }^{\circ} \mathrm{C}$ for $0.5 \mathrm{~h}$.

$\mathrm{X}$-ray diffraction (XRD) measurements were performed using a Bruker D8 ADVANCE $\mathrm{X}$-ray diffractometer (Bruker Company, Bremen, Germany) equipped with a $\mathrm{Cu} \mathrm{K} \alpha \mathrm{X}$-ray tube operating at $40 \mathrm{kV}$ and $40 \mathrm{~mA}$ in the $2 \theta$ scan range between $10^{\circ}$ and $90^{\circ}$.

X-ray photoelectron spectroscopy (XPS) spectra were recorded using a Kratos Axis Ultra DLD spectrometer (Kratos Company, Manchester, UK) employing a monochromated Al-K $\alpha$ X-ray source, hybridoptics, and a multi-channel plate and delay line detector. The peak area corresponded to its valence content.

The liquid catalysts were analyzed by transmission electron microscopy (TEM). A drop of the liquid catalyst was allowed to evaporate on a holey carbon film supported by a 300-mesh copper TEM grid. Bright-field and annular darkfield imaging experiments were carried out using a JEM2100F transmission electron microscope (Nippon Electronics Co., Ltd., Tokyo, Japan).

\section{Results and Discussion}

\subsection{Results}

Previously, we have reported that the addition second metal can improve the performance of NC in acetylene dimerization [14-16]. Inspired by these results, we test the catalytic activities through six types of catalysts presented in Figure 1. Although good acetylene dimerization activity was observed with the use of NC, the selectivity for MVA was relatively poor. Interestingly, after incorporating a second metal component, the catalytic selectivity for MVA was significantly enhanced. The selectivity to MVA of catalysis were in the order of $\mathrm{Zr}_{5} / \mathrm{NC}>\mathrm{Zr}_{1} / \mathrm{NC}>\mathrm{Zr}_{4} / \mathrm{NC}>\mathrm{Zr}_{2} / \mathrm{NC}>\mathrm{Zr}_{3} / \mathrm{NC}>\mathrm{NC}$. 


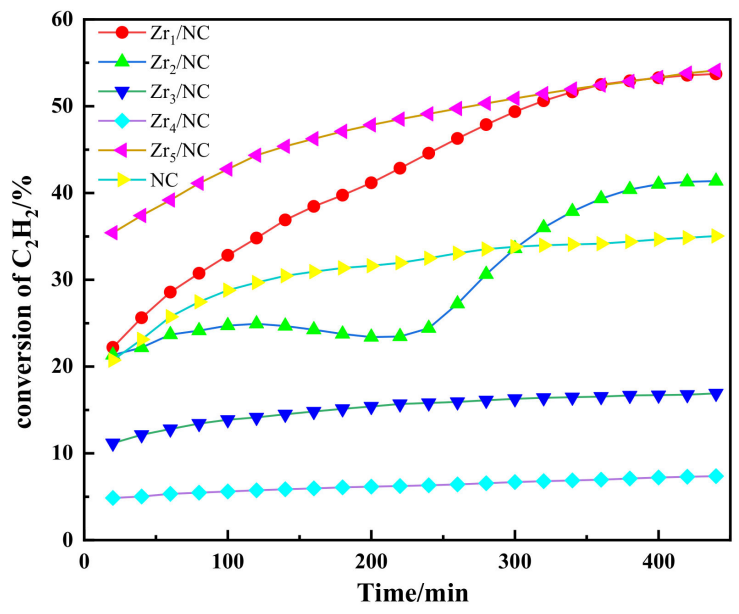

(a)

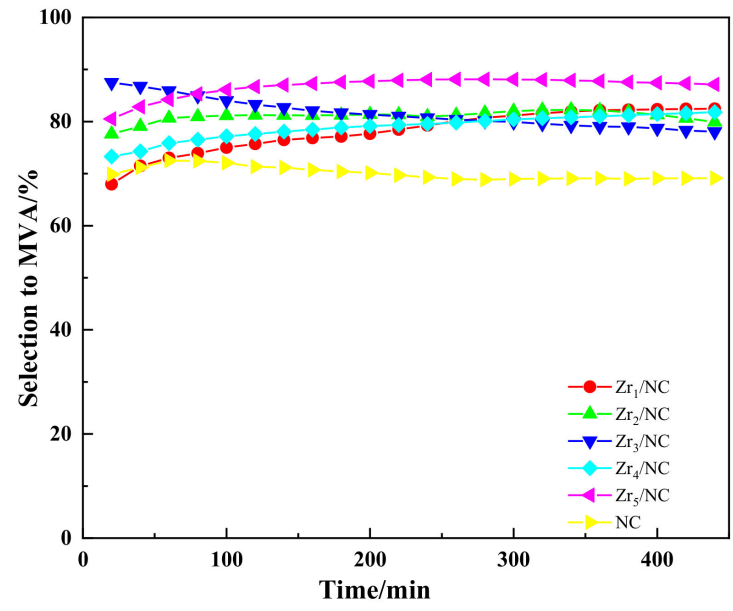

(b)

Figure 1. Catalytic performance of $\mathrm{NC}$ and $\mathrm{Zr}_{X} / \mathrm{NC}$. (a) $\mathrm{C}_{2} \mathrm{H}_{2}$ conversion with time on stream, and (b) MVA selectivity with time on stream. Reaction conditions; temperature $(\mathrm{T})=80^{\circ} \mathrm{C}$ and $\mathrm{C}_{2} \mathrm{H}_{2}$ gas hourly space velocity $(\mathrm{GHSV})=110 \mathrm{~h}^{-1}$.

It is worth noting that $\mathrm{NC}$, without the addition of zirconium acetylacetonate, showed a relatively stable activity. However, its selectivity for MVA exhibited a downward trend, and it remained at a low level of about $68 \%$ (Figure $1 \mathrm{~b}$ ). The $\mathrm{ZrX} / \mathrm{NC}$ catalyst exhibited a relatively better selectivity for MVA with the addition of $0.001 \mathrm{~mol}$ zirconium metal additives. Among them, the zirconium-acetylacetonate-incorporated NC (denoted as $\mathrm{Zr}_{5} / \mathrm{NC}$ ) catalyst exhibited the best performance, with an almost $87.4 \%$ MVA selectivity and a $\mathrm{C}_{2} \mathrm{H}_{2}$ conversion greater than $53.3 \%$ after $8 \mathrm{~h}$. The zirconium-nitrate-pentahydrate-incorporated $\mathrm{NC}$ (denoted as $\mathrm{Zr}_{1} / \mathrm{NC}$ ) showed a similar catalytic performance to that of $\mathrm{Zr}_{5} / \mathrm{NC}$.

This result may have been due to the $\mathrm{Zr}^{4+}$ ions, as the $\mathrm{NO}_{3}{ }^{-}$and $\mathrm{Cu}^{+}$did not coexist under acidic conditions, and acetylacetone thermally decomposed at the reaction temperature. However, for the zirconium-oxychloride-octahydrate-incorporated NC (denoted as $\mathrm{Zr}_{3} / \mathrm{NC}$ ) and the zirconium-chloride-incorporated NC (denoted as $\mathrm{Zr}_{4} / \mathrm{NC}$ ) under similar conditions, a more restrained effect on the conversion of $\mathrm{C}_{2} \mathrm{H}_{2}$ was observed. Such a result may have been due to the greater amount of $\mathrm{Cl}^{-}$brought in Nieuwland catalyst system, which lowered the $\mathrm{C}_{2} \mathrm{H}_{2}$ conversion.

Since $\mathrm{Zr}_{5}$ does not possess stable chemical bonds, it can easily be decomposed to acetylacetone $\left(C_{1}\right)$, acetone $\left(C_{2}\right)$, and acetic acid $\left(C_{3}\right)$ in the catalytic system. Hence, to verify the effects of the $Z_{5}$ promoter ligand on the reaction, $C_{1}, C_{2}$, and $C_{3}$ were analyzed. The catalytic performance of $\mathrm{C}_{X} / \mathrm{NC}$ under similar reaction conditions to those used for acetylene dimerization is shown in Figure $2 . \mathrm{C}_{2} / \mathrm{NC}$ and $\mathrm{C}_{3} / \mathrm{NC}$ showed no significant performance enhancements. $\mathrm{C}_{1} / \mathrm{NC}$ showed a good activity of $37.0 \%$ and a relatively good MVA selectivity of $80.3 \%$ after $480 \mathrm{~min}$. During the reaction, it is hypothesized that coordination between $C_{1}$ and the active center of the catalyst may have occurred. As such, this may have reduced the amount of DVA produced due to MVA trimerization, therefore improving the catalytic activity and selectivity of the catalyst. 


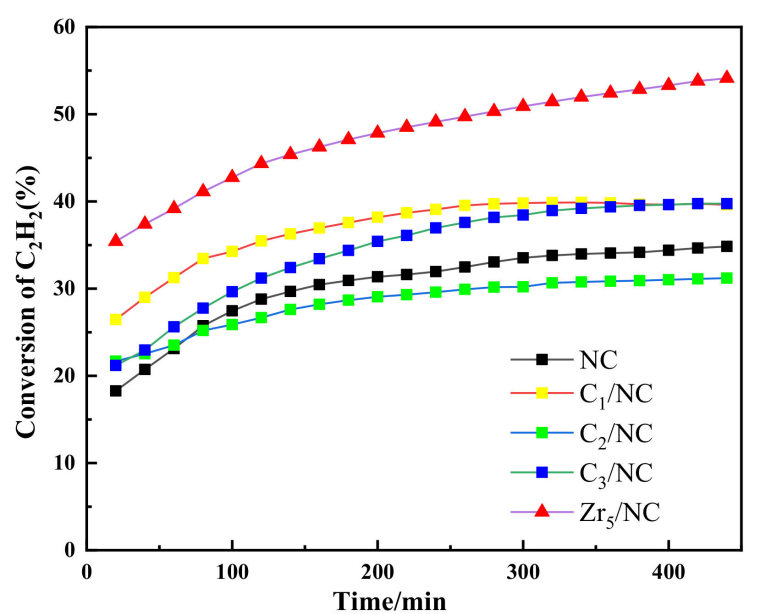

(a)

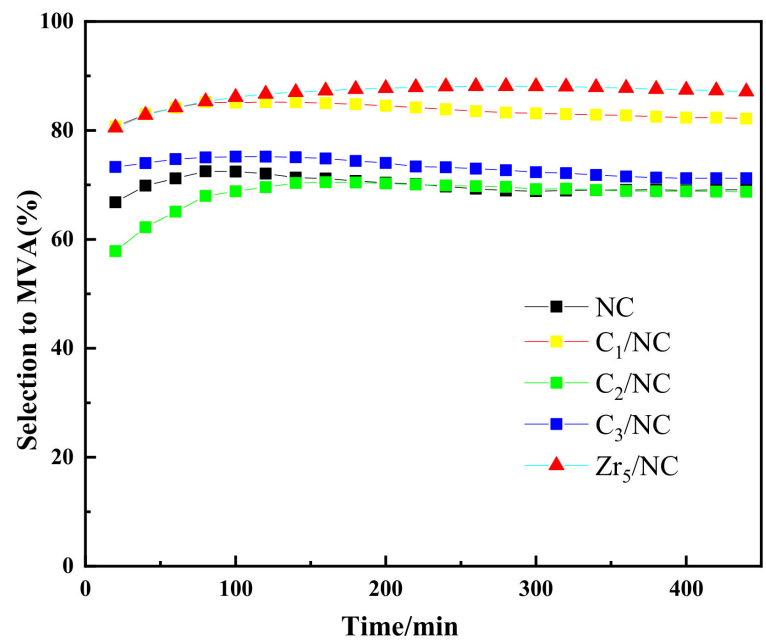

(b)

Figure 2. Catalytic performance of $\mathrm{NC}$ and $\mathrm{C}_{X} / \mathrm{NC}$. (a) $\mathrm{C}_{2} \mathrm{H}_{2}$ conversion with time on stream, and (b) MVA selectivity with time on stream. Reaction conditions; temperature $(\mathrm{T})=80^{\circ} \mathrm{C}, \mathrm{C}_{2} \mathrm{H}_{2}$ gas hourly space velocity $(\mathrm{GHSV})=110 \mathrm{~h}^{-1}$.

\subsection{Characterization and Analysis of Catalyst}

To determine the nature of the $\mathrm{Zr}_{5} / \mathrm{NC}$ catalyst, detailed structural and chemical analyses were conducted using a combination of characterization techniques.

\subsubsection{Composition of Catalyst}

The TGA and (differential thermogravimetry) DTG curves of the fresh and used NC and those of the $\mathrm{Zr}_{5} / \mathrm{NC}$ catalysts are shown in Figure 3a,b, respectively. According to Figure $3 \mathrm{a}$, neither the fresh nor the used NC catalyst showed observable mass losses before reaching $150{ }^{\circ} \mathrm{C}$. This result indicated that there was a small amount of water adsorbed on the surface of the catalyst. Within the temperature range of $150-400{ }^{\circ} \mathrm{C}$, there was a gradual mass loss for the fresh NC catalyst (whereby it reached $30.87 \%$ ), and this was attributed to the loss of $\mathrm{NH}_{4} \mathrm{Cl}$. As the temperature exceeded $400{ }^{\circ} \mathrm{C}$, there was a rapid decrease in the mass of the catalyst due to the decomposition of $\mathrm{CuCl}$. In contrast, the used NC catalyst underwent a significant weight loss of $26.25 \%$ in the temperature range of $150-400{ }^{\circ} \mathrm{C}$, which was attributed to the loss of $\mathrm{NH}_{4} \mathrm{Cl}$ and $\mathrm{C}_{2} \mathrm{H}_{2}$. At the temperature range of $150-400{ }^{\circ} \mathrm{C}$ (with the majority of the mass loss in the range of $150-320^{\circ} \mathrm{C}$ ), the mass losses observed for both the fresh and used NC catalysts were mainly due to the decomposition of $\mathrm{NH}_{4} \mathrm{Cl}$.Upon the incorporation of $\mathrm{Zr}_{5}$, there was a shaper drop in the mass for both the fresh and used $\mathrm{Zr}_{5} / \mathrm{NC}$ (Figure $3 \mathrm{~b}$ ) in the temperature range of $150-340{ }^{\circ} \mathrm{C}$, which was attributed to the coordination of $\mathrm{C}_{3}$ to the active center. When the temperature exceeded $475^{\circ} \mathrm{C}$, there was a significant mass loss in the catalyst, which was mainly due to the decomposition of $\mathrm{CuCl}$. The comparison of the results in Figure $3 \mathrm{a}, \mathrm{b}$ shows that the decomposition temperature of $\mathrm{NH} 4 \mathrm{Cl}$ was lower after the addition of $\mathrm{Zr} 5$, while the decomposition temperature of $\mathrm{CuCl}$ increased. According to the TGA and DTG curves, $\mathrm{Zr}_{5}$ may have promoted the stability of the $\mathrm{NH}_{4} \mathrm{Cl}$ and $\mathrm{CuCl}$, which accounted for the reduced mass loss in the range of $150-400{ }^{\circ} \mathrm{C}$ and the higher decomposition temperature of $\mathrm{CuCl}$. 


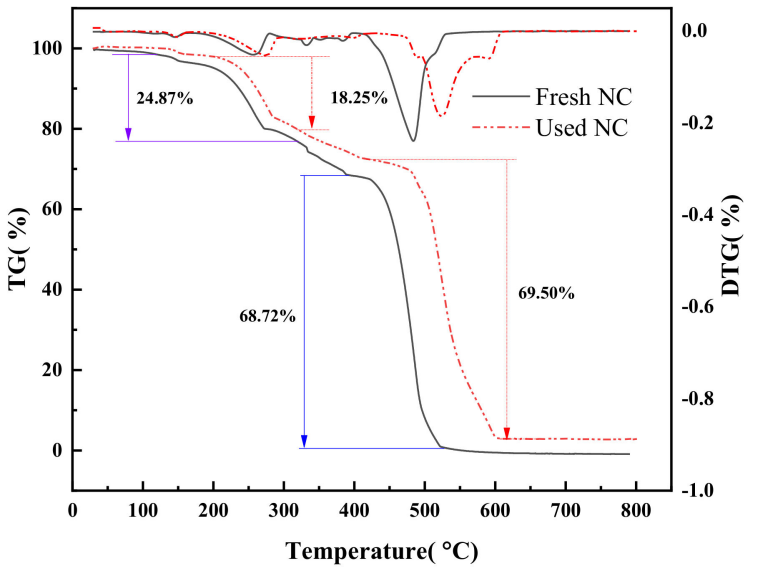

(a)

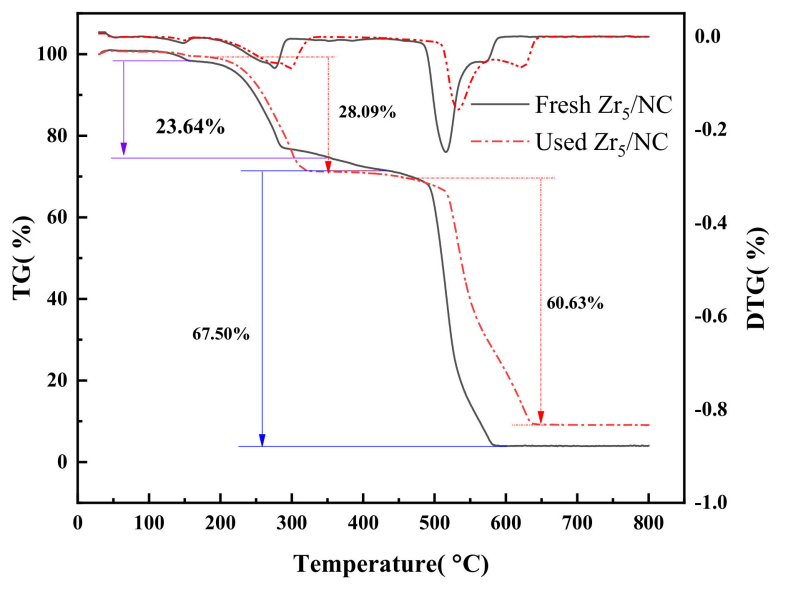

(b)

Figure 3. TGA and DTG curves of catalysts. (a) TG result of $\mathrm{NC}$, and (b) TG result $\mathrm{Zr}_{5} / \mathrm{NC}$.

\subsubsection{Effects of Additional Components on Catalytic Performance of NC Catalyst}

The $\mathrm{H}_{2}$-TPR profile of the fresh NC catalyst revealed two characteristic reduction bands between $400{ }^{\circ} \mathrm{C}$ and $696{ }^{\circ} \mathrm{C}$, the $\mathrm{Cu}^{2+}$ and $\mathrm{Cu}^{+}$in the $\mathrm{Cl}^{-}$rich environment are harder to reduce, as copper ions can form complexes with chloride ions to improve antireduction stability, respectively (shown in Figure 4a) [23-27]. After the reaction (used NC catalyst), the $\mathrm{C}_{2} \mathrm{H}_{2}$ destroy the complex formed by copper ion and chloride ion, reduce its reduction temperature, lead to the peak of $\mathrm{Cu}^{2+}$ and $\mathrm{Cu}^{+}$shifted left. The $\mathrm{H}_{2}$-TPR profile of used $\mathrm{NC}, \mathrm{Zr}_{5} / \mathrm{NC}$ and used $\mathrm{Zr}_{5} / \mathrm{NC}$ shows another reduction peak at $400-550{ }^{\circ} \mathrm{C}$ caused by free copper ions.

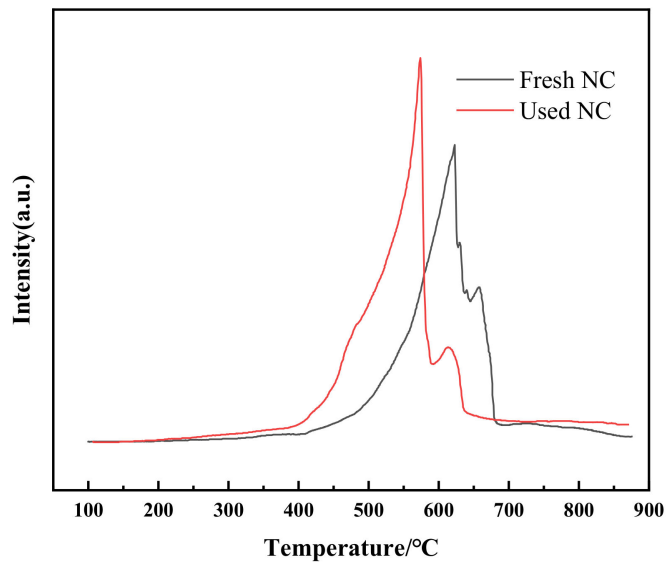

(a)

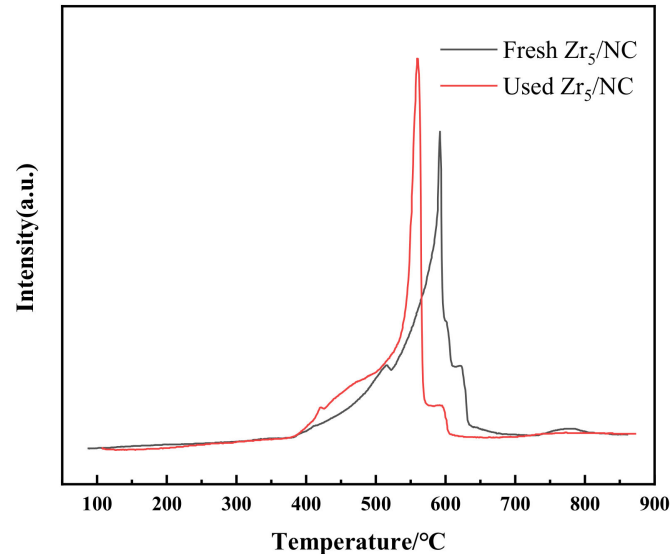

(b)

Figure 4. $\mathrm{H}_{2}$-TPR profiles. (a) The intensity signal with temperature of NC, and (b) The intensity signal with temperature of $\mathrm{Zr}_{5} / \mathrm{NC}$.

The results in Figure 4a,b show that the widths of both the $\mathrm{Cu}^{+}$and $\mathrm{Cu}^{2+}$ reduction peaks became narrower after the addition of $\mathrm{Zr}_{5}$, it is reasonable to conclude that the complexes in the $\mathrm{Zr}_{5} / \mathrm{NC}$ catalyst system were purer, which was consistent with the conclusions drawn from the TGA results. The used catalyst may have formed a specific complex with acetylene, which reduced its reduction temperature.

Previously report shown $\mathrm{pH}$ of the catalyst solution have an effect on catalytic activity [28]. As shown in Table $1, \mathrm{Zr}_{5} / \mathrm{NC}$ possessed a lower initial $\mathrm{pH}$ value than $\mathrm{NC}$, and 
the $\mathrm{pH}$ of both catalytic systems remained relatively stable with time. This result was due to the instability of $Z_{5}$ in the Nieuwland catalytic system, and the catalyst could be easily decomposed to produce acidic $C_{3}$, which could reduce the initial $\mathrm{pH}$ of the $\mathrm{Zr}_{5} / \mathrm{NC}$ solution.

Table 1. $\mathrm{pH}$ of $\mathrm{NC}$ and $\mathrm{Zr}_{5} / \mathrm{NC}$ at different time intervals during the acetylene dimerization reaction.

\begin{tabular}{ccccccccc}
\hline \multirow{2}{*}{ Sample } & \multicolumn{7}{c}{$\mathbf{p H}$} \\
\cline { 2 - 10 } & $\mathbf{1} \mathbf{h}$ & $\mathbf{2} \mathbf{h}$ & $\mathbf{3} \mathbf{h}$ & $\mathbf{4} \mathbf{h}$ & $\mathbf{5} \mathbf{h}$ & $\mathbf{6} \mathbf{h}$ & $\mathbf{7} \mathbf{h}$ & $\mathbf{8} \mathbf{~ h}$ \\
\hline $\mathrm{NC}$ & 1.2 & 1.2 & 1.3 & 1.2 & 1.2 & 1.2 & 1.3 & 1.3 \\
$\mathrm{Zr}_{5} / \mathrm{NC}$ & 1.1 & 1.1 & 1.2 & 1.2 & 1.2 & 1.3 & 1.2 & 1.3 \\
\hline
\end{tabular}

\subsubsection{Change in Valence of Active Component during Reaction}

Figure 5 shows the XRD patterns of the fresh and used $\mathrm{NC}$ and $\mathrm{Zr}_{5} / \mathrm{NC}$ catalysts. The result shown that the main component between them is $\mathrm{Cu}_{112} \mathrm{Cl}_{168}$, indicating that $\mathrm{Cu}_{112} \mathrm{Cl}_{168}$ may be the active component in the catalyst. With the addition of $\mathrm{Zr}_{5}$, other impurity peaks in the catalyst decrease, such as $2 \theta=30.38$, and the XRD pattern of $\mathrm{Zr}_{5} / \mathrm{NC}$ was more consistent with $\mathrm{Cu}_{112} \mathrm{Cl}_{168}$.

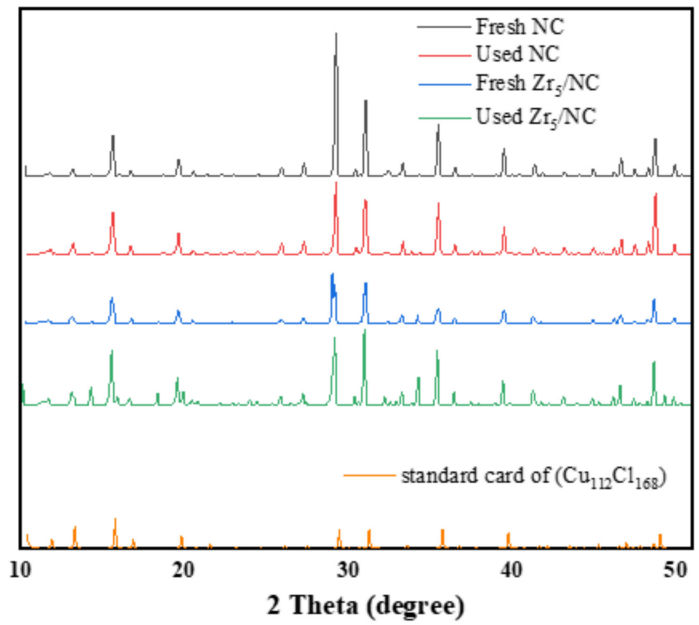

Figure 5. XRD spectra. Standard card of $\mathrm{Cu}_{112} \mathrm{Cl}_{168}$ : Cambridge Crystallographic Data Centre (CCDC) and the deposition number is 2092361.

X-ray photoelectron spectroscopy can provide the chemical state and distribution of the active component (i.e., $\mathrm{Cu}$ ) in the catalyst before and after the reaction were shown in the Figure 6a,b [29,30]. Thus, Figure 6a curves were deconvoluted to determine the ratio of each $\mathrm{Cu}$ species in the catalyst. During the preparation and storage of the catalysts, $\mathrm{Cu}^{+}$ could be reduced to $\mathrm{Cu}^{2+}$. As such, the active component $\mathrm{Cu}$ in the catalyst was composed of a large amount of $\mathrm{Cu}^{+}$and a small amount of $\mathrm{Cu}^{2+}(\mathrm{CuCl}$ and $\mathrm{HCl}$ will react in hot water: $\left.\mathrm{CuCl}+\mathrm{HCl}=\mathrm{H}\left[\mathrm{CuCl}_{2}\right]\right)$. For the fresh $\mathrm{NC}$ and $\mathrm{Zr}_{5} / \mathrm{NC}$, the contents of $\mathrm{Cu}^{+}$were 76.27 and $71.20 \%$, respectively (as shown in Table 2), while the contents of $\mathrm{Cu}^{+}$in the used $\mathrm{NC}$ and $\mathrm{Zr}_{5} / \mathrm{NC}$ catalysts were $72.78 \%$ and $68.64 \%$, respectively. Combining the results of XRD, it is found that the closer the content of $\mathrm{Cu}^{+} / \mathrm{Cu}^{2+}$ is to $\mathrm{Cu}_{112} \mathrm{Cl}_{168}$, the better the catalytic activity. The Figure $6 \mathrm{~b}$ shown the existence of different elements in the catalysis. In addition to the surface characterization by XPS analysis, the result obtained from ICP-OES also indicated that the loss ratio of $\mathrm{Cu}$ after the reaction was small. 


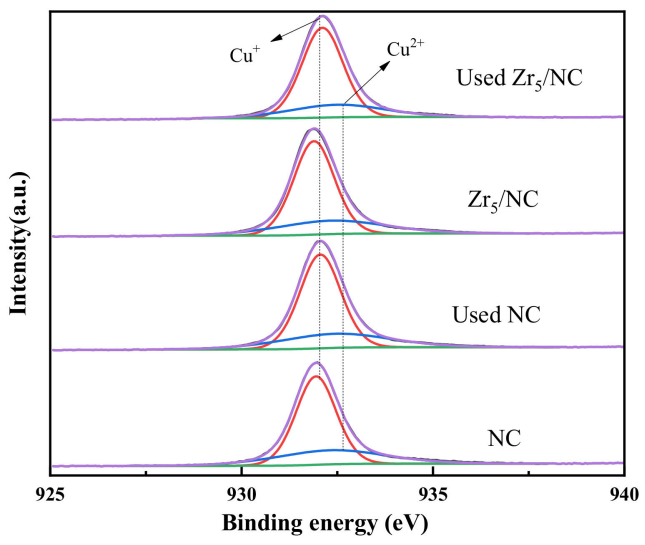

(a)

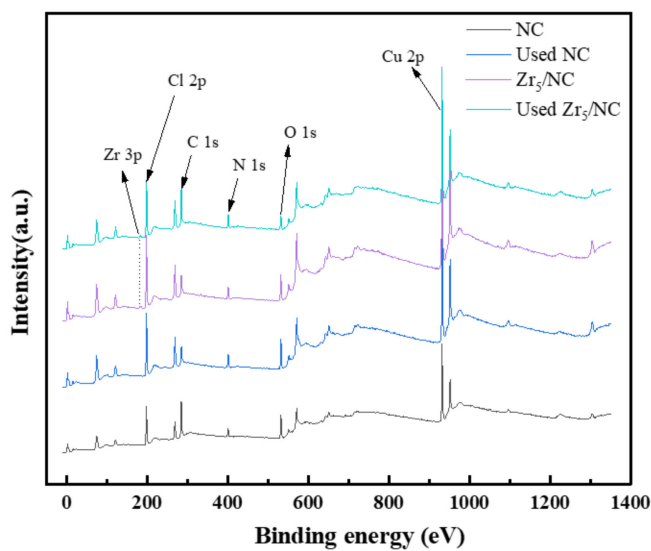

(b)

Figure 6. XPS spectra of catalysts, (a) the Cu2p spectra and (b) XPS survery spectra.

Table 2. Relative contents and binding energies of $\mathrm{Cu}^{+}$and $\mathrm{Cu}^{2+}$ in the fresh and used catalysts as determined by XPS and ICP-OES ( ${ }^{\mathrm{a}}$ denotes the determination using XPS, and ${ }^{\mathrm{b}}$ denotes the determination using ICP-OES).

\begin{tabular}{|c|c|c|c|c|}
\hline \multirow{2}{*}{ Sample } & \multicolumn{2}{|c|}{ Area\% $(\mathrm{Cu})^{a}$} & \multirow{2}{*}{$\begin{array}{l}\mathrm{Cu} \% \text { (Metal Ion } \\
\text { Content) }\end{array}$} & \multirow{2}{*}{$C u$ Loss $(\%)^{b}$} \\
\hline & $\mathrm{Cu}^{+}$ & $\mathrm{Cu}^{2+}$ & & \\
\hline Fresh NC & 76.27 & 26.73 & 40.77 & \\
\hline Used NC & 72.78 & 27.22 & 40.35 & 1.03 \\
\hline Fresh $\mathrm{Zr}_{5} / \mathrm{NC}$ & 71.20 & 28.80 & 38.46 & \\
\hline Used $\mathrm{Zr}_{5} / \mathrm{NC}$ & 68.64 & 31.36 & 37.19 & 3.30 \\
\hline
\end{tabular}

\subsubsection{Morphology and Structure of Catalysis}

Figure 7 shows the morphological characteristics of the catalyst after starting the reaction and $8 \mathrm{~h}$ after the reaction. Numerous black polymers can be clearly observed in the NC catalyst in the reaction tube after eight hours of reaction. In contrast, no precipitate was evident in the reaction tube with $\mathrm{Zr}_{5} / \mathrm{NC}$. This observation verified that the addition of $\mathrm{Zr}_{5}$ could reduce the production of polymer and the number of active centers. It is worth noting that a perfect bubbling effect could not be achieved due to the highly viscous nature of the catalyst, which resulted in uneven contact between the active components and the reactants. As shown in Figure $7 c, d$, after adding $Z_{5}$, the system was more likely to form bubbles in the solution under the same reaction conditions. As such, this reduced the residence time of acetylene in the catalyst, increased the contact area between these two components, reduced the formation of polymers, and improved the catalytic performance of the catalyst.

Transmission electron microscopy (TEM) was conducted to investigate the morphology and structure of the catalyst after starting the reaction (Figure $8 \mathrm{a}, \mathrm{c}$ ) and after reacting for $8 \mathrm{~h}$ (Figure $8 b, d$ ). During the initial stage of the reaction, the active components were uniformly dispersed in the solvent for both $\mathrm{NC}$ and $\mathrm{Zr}_{5} / \mathrm{NC}$, and no black polymer was observed (Figure $8 \mathrm{a}, \mathrm{c}$ ). However, after reacting for $8 \mathrm{~h}$, morphological changes were evident for NC, whereby severe agglomeration was observed (Figure 8b), as MVA stuck to the active centers and continued to polymerize with acetylene. However, there was no evident agglomeration for the $\mathrm{Zr}_{5} / \mathrm{NC}$ catalyst after reacting for $8 \mathrm{~h}$, which may have been attributed to the addition of $Z_{5}$. The resultant high polymer was attached to the surfaces of the active components, which could affect the contact between acetylene and the catalyst. This could then reduce the performance of the catalyst. The conclusion obtained from the TEM results was consistent with that obtained from the above-mentioned analyses. 


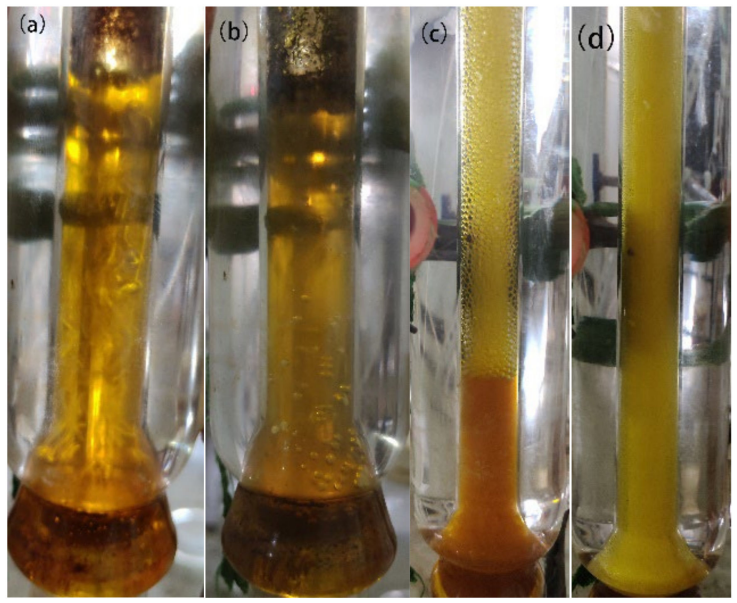

Figure 7. Photographic images of the bubble column reactors containing $\mathrm{NC}(\mathbf{a}, \mathbf{b})$ and $\mathrm{Zr}_{5} / \mathrm{NC}_{(\mathbf{c}, \mathbf{d})}$ before and after the reaction.
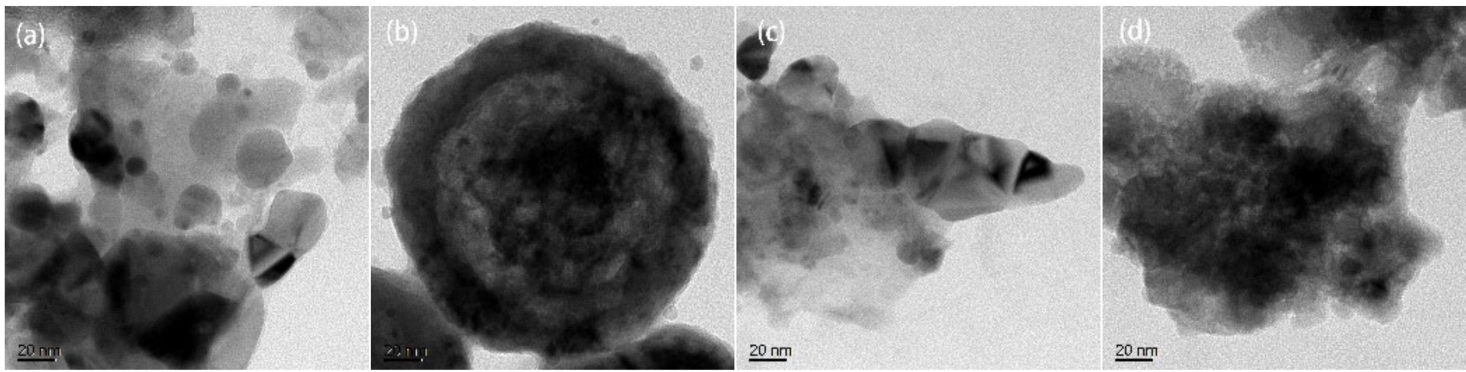

Figure 8. TEM images. (a) the fresh $\mathrm{NC}$, (b) the used $\mathrm{NC}$, (c) the fresh $\mathrm{Zr}_{5} / \mathrm{NC}$, and (d) the used $\mathrm{Zr}_{5} / \mathrm{NC}$.

\section{Conclusions}

The catalysis of acetylene dimerization over $\mathrm{Zr}_{5} / \mathrm{NC}$ catalysts showed that the addition of a second metal $\mathrm{Zr}$ component in the catalyst could significantly enhance its MVA selectivity. The best catalytic performance was obtained over the $\mathrm{Zr}_{5} / \mathrm{NC}$ catalyst, with an acetylene conversion of $53.3 \%$ and MVA selectivity of $87.4 \%$. The addition of $\mathrm{Zr}_{5}$ can promote the formation of $\mathrm{Cu}_{112} \mathrm{Cl}_{168}$ and make the active components of the catalyst purer, thereby promoting the improvement of the catalytic performance of the catalyst.

Author Contributions: Conceptualization, J.Z. and L.G.; methodology, L.Z.; software, L.Z.; validation, L.Z., D.L. and R.L.; formal analysis, L.Z.; investigation. L.Z.; data curation, L.Z.; writingoriginal draft preparation, L.Z.; writing — review and editing, L.Z.; supervision, L.G.; project administration, J.Z.; funding acquisition, L.G. All authors have read and agreed to the published version of the manuscript.

Funding: This research was funded by National Natural Science Foundation of China (NO.21776179).

Institutional Review Board Statement: Not applicable.

Informed Consent Statement: Not applicable.

Data Availability Statement: Not applicable.

Acknowledgments: We acknowledge the National Natural Science Foundation of China and Key Laboratory for Green Processing of Chemical Engineering of Xinjiang Bingtuan for their support.

Conflicts of Interest: The authors declare no conflict of interest.

Sample Availability: Samples of the compounds are not available from the authors. 


\section{References}

1. Bridgewater, E. Neoprene, The Chloroprene Rubber. Ind. Eng. Chem. 1940, 32, 1155-1156. [CrossRef]

2. Cui, X. Production and consumption of neoprene at home and abroad. Rubber Sci. Technol. 2012, 12, 5. [CrossRef]

3. Vasil'eva, V.G.; Klebanskii, A.L. The Structure of Synthetic Types of Rubber. Polychloroprenes. Rubber Chem. Technol. 1937, 10, 126-134. [CrossRef]

4. Ismail, H.; Leong, H.C. Curing characteristics and mechanical properties of natural rubber/chloroprene rubber and epoxidized natural rubber/chloroprene rubber blends. Polym. Test. 2001, 20, 509-516. [CrossRef]

5. Nieuwland, J.A.; Calcott, W.S.; Downing, F.B.; Carter, A.S. Acetylene Polymers and Their Derivatives. I. The Controlled Polymerization of Acetylene. J. Am. Chem. Soc. 1931, 53, 4197-4202. [CrossRef]

6. Carothers, W.H.; Williams, I.; Collins, A.M.; Kirby, J.E. Acetylene Polymers and Their Derivatives. II. A New Synthetic Rubber: Chloroprene and Its Polymers. J. Am. Chem. Soc. 1931, 53, 4203-4225. [CrossRef]

7. Cummings, C. Neoprene and nylon stockings: The legacy of Wallace Hume Carothers. J. Chem. Educ. 1984, 61, 241-242. [CrossRef]

8. Maggio, G.; Cacciola, G. A variant of the Hubbert curve for world oil production forecasts. Energy Policy 2009, 37, 4761-4770. [CrossRef]

9. Tachiyama, T.; Yoshida, M.; Aoyagi, T.; Fukuzumi, S. Deuterium kinetic isotope effects and H/D exchange in dimerization of acetylene with a Nieuwland catalyst in aqueous media. J. Phys. Org. Chem. 2008, 21, 510-515. [CrossRef]

10. Tokita, Y.; Okamoto, A.; Nishiwaki, K.; Kobayashi, M.; Nakamura, E. Kinetics of Copper(I)-Catalyzed Dimerization and Hydration of Acetylene in Water. Bull. Chem. Soc. Jpn. 2004, 77, 1395-1399. [CrossRef]

11. Changyuan, T.; Rong, H.; Zuohua, L.; Jun, D.; Xing, F.; Xiaoxia, Z.; Renlong, L.; Jinjing, T.; Zhaoming, X.; Dagui, S. Method for Preparing Vinyl Acetylene by Strengthening Acetylene Dimerization by Electric Field. Patent CN 102267856 A, 7 December 2011

12. Zhang, Q.; You, Y.; Xie, J.; Dai, B.; Zhang, J. Effect of high-speed shear reactor in liquid phase catalytic reaction of acetylene dimerization. J. Shihezi Univ. (Nat. Sci.) 2019, 37, 6. [CrossRef]

13. Changyuan, T.; Lijuan, Y.; Jun, D.; Xing, F.; Zuohua, L.; Dagui, S.; Renlong, L.; Zhaohong, Z.; Jin-jing, T.; Xiaoxia, Z. GrapheneEnhanced Acetylene Dimerization Catalyst and Application Method. Patent CN103691470 A, 2 April 2014.

14. Lu, J.; Xie, J.; Liu, H.; Liu, P.; Liu, Z.; Dai, B. Strontium Chloride Modified Nieuwland Catalyst in the Dimerization of Acetylene to Monovinylacetylene. Asian J. Chem. 2014, 26, 4. [CrossRef]

15. Lu, J.; Liu, H.; Xie, J.; Liu, P.; Liu, Z. Study on Catalytic Activity Catalysis in of Zinc(II)-Copper(I) Acetylene Dimerization Collaborative Bimetallic l action. J. Shihezi Univ. (Nat. Sci.) 2014, 32, 4. [CrossRef]

16. Liu, H.; Xie, J.; Liu, P.; Dai, B. Effect of $\mathrm{Cu}^{+} / \mathrm{Cu}^{2+}$ Ratio on the Catalytic Behavior of Anhydrous Nieuwland Catalyst during Dimerization of Acetylene. Catalysts 2016, 6, 120. [CrossRef]

17. Zhang, Q.; Li, C.; Luo, J.; Xie, J.; Zhang, J.; Dai, B. Hydrazinylbenzenesulfonic Acid-Modified Nieuwland Catalyst for Acetylene Dimerization Reaction. Catal. Lett. 2020, 150, 1766-1773. [CrossRef]

18. Zhang, Q.; Li, C.; Luo, J.; Xie, J.; Zhang, J.; Dai, B. A novel risedronic acid-modified Nieuwland catalyst for acetylene dimerization Catal. Commun. 2020, 136, 5. [CrossRef]

19. Lu, J.; Liu, H.; Xie, J.; Liu, P.; Dai, B.; Liu, Z. Effect of polyethylene glycol/Nieuwland catalyst on acetylene dimerization re-action. Chem. Eng. 2015, 43, 5. [CrossRef]

20. You, Y.; Luo, J.; Xie, J.; Dai, B. Effect of Iminodiacetic Acid-Modified Nieuwland Catalyst on the Acetylene Dimerization Reaction Catalysts 2017, 7, 394. [CrossRef]

21. Liu, J.; Han, M.; Wang, Z. Effect of solvent on catalytic performance of anhydrous catalyst in acetylene dimerization to monovinylacetylene. J. Energy Chem. 2013, 22, 599-604. [CrossRef]

22. Liu, J.; Han, M.; Wang, Z. Studies on the Catalytic Performance of the Nieuwland Catalyst and Anhydrous Catalyst in the Dimerization of Acetylene to Monovinylacetylene. Adv. Mater. Res. 2012, 550-553, 312-316. [CrossRef]

23. Li, C.; Luo, J.; Zhang, Q.; Xie, J.; Zhang, J.; Dai, B. Gas-solid acetylene dimerization over copper-based catalysts. New J. Chem. 2019, 43, 13608-13615. [CrossRef]

24. Zeng, Q.; Xu, G.; Zhang, L.; Lin, H.; Lv, Y.; Jia, D. Porous CuO nanofibers derived from a Cu-based coordination polymer as a photocatalyst for the degradation of rhodamine B. New J. Chem. 2018, 42, 7016-7024. [CrossRef]

25. Li, C.; Xie, J.; Zhang, J.; Dai, B. Nitrogen-Modified Activated Carbon Supported Cu(II)Cu(I)/NAC Catalysts for Gas-Solid Acetylene Dimerization. Catal. Lett. 2021, 151, 2990-2995. [CrossRef]

26. Reddy Kannapu, H.P.; Mullen, C.A.; Elkasabi, Y.; Boateng, A.A. Catalytic transfer hydrogenation for stabilization of bio-oil oxygenates: Reduction of p-cresol and furfural over bimetallic Ni-Cu catalysts using isopropanol. Fuel Process. Technol. 2015, 137, 220-228. [CrossRef]

27. Lin, C.; Li, R. Study on the temperature-programmed reduction of $\mathrm{CuCl}_{2} / \mathrm{NaY}$ system heating the monolayer dispersion state. J. Shenyang Normal Univ. (Nat. Sci. Ed.) 2002, 20, 202-205. [CrossRef]

28. Deng, G.; Li, J.; Chen, R. Dimerization kinetics and reaction mechanism of acetylene in the catalytic system of CuCl-KCl-HCl-H $\mathrm{H}_{2} \mathrm{O}$ The relationship between reaction rate and catalyst acidity. China Synth. Rubber Ind. 1983, 12, 3.

29. You, Y.; Luo, J.; Xie, J.; Zhang, J.; Dai, B. Effects of Coordination Ability of Nitrogen-Containing Carboxylic Acid Ligands on Nieuwland Catalyst. Catalysts 2018, 8, 337. [CrossRef]

30. Zhang, Q.; Liu, X.; Luo, J.; Ma, C.; Xu, C. Complexation effect of copper(ii) with HEDP supported by activated carbon and influence on acetylene hydration. New J. Chem. 2021, 45, 1712-1720. [CrossRef] 